\title{
The 2016 Meinong earthquake to TEM PSHA2015
}

\author{
Ya-Ting Lee ${ }^{1, *}$, Yu-Ju Wang ${ }^{2}$, Chung-Han Chan ${ }^{3}$, and Kuo-Fong $\mathrm{Ma}^{1}$ \\ ${ }^{1}$ Department of Earth Sciences, National Central University, Taoyuan City, Taiwan \\ ${ }^{2}$ Institute of Nuclear Energy Research, Atomic Energy Council, Taoyuan City, Taiwan \\ ${ }^{3}$ Earth Observatory of Singapore, Nanyang Technological University, Singapore
}

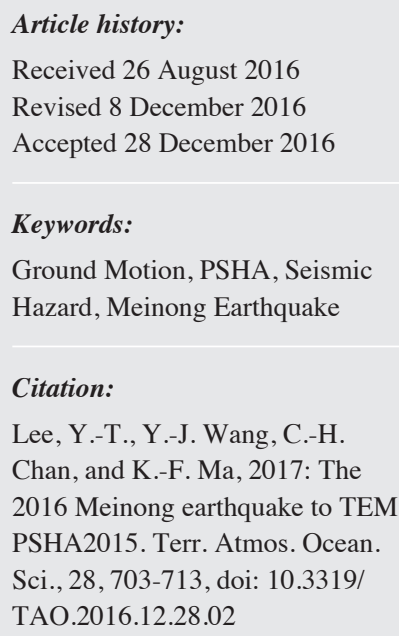

\begin{abstract}
On 6 February 2016 (UTC 19:57), the Meinong earthquake with Richter magnitude $\left(\mathrm{M}_{\mathrm{L}}\right) 6.6$ struck southern Taiwan and caused hundreds of damaged buildings, resulting in 117 casualties. We investigated the relationship between the damaged buildings and the ground motion in the forms of peak ground acceleration (PGA), peak ground velocity (PGV), pseudo-spectral acceleration (SA) at $0.3 \mathrm{~s}$ (SA0.3), $1.0 \mathrm{~s}$ (SA1.0), and shaking duration to identify which ground motion parameter most represents building damage. PGV and SA1.0 present better correlation with consequent damage. The Intensity converted from PGV presents better correlation to the damage than PGA. We disaggregated the TEM PSHA2015 hazard contribution to the Meinong earthquake damage region (Southern Taiwan) from different seismic source typologies to clarify the seismic source contributing to the hazard. The hazards contributed by the Meinong earthquake were 16, 26, and 23\% for PGA, SA0.3, and SA1.0, respectively. The predicted seismic hazard source areas were 38,61 , and $75 \%$ for PGA, SA0.3, and SA1.0, respectively, for the PSHA with a return period of 475 years. This result indicates that the 2016 Meinong earthquake did partially diminish the seismic hazard potential in southern Taiwan. However, more than about $80 \%$ of the seismic hazard potential, especially the fault sources were not yet released. These values suggest that the seismic hazard potential in southern Taiwan remains high regardless of the 2016 Meinong earthquake.
\end{abstract}

\section{INTRODUCTION}

On 6 February 2016, an earthquake with a Richter magnitude scale of 6.6 (moment magnitude of 6.4 announced by United States Geological Survey, http://earthquake. usgs.gov/earthquakes/eventpage/us20004y6h\#executive) occurred in southern Taiwan. According to the Central Weather Bureau report (CWB), the earthquake hypocentre $\left(120.54^{\circ} \mathrm{E}, 22.92^{\circ} \mathrm{N}\right)$ is in the Meinong District of Kaohsiung City at a depth of $14.6 \mathrm{~km}$. The earthquake caused widespread damage, resulting in 117 casualties. Building damage mainly occurred in the Tainan region. The collapse of a residential building, named the Weiguan Jinlong Building, caused 115 casualties. Overall, 551 people were injured from the disaster which struck Taiwan during the most important family holiday, Chinese New Year Eve (detailed earthquake disaster information can be found in the official

\footnotetext{
* Corresponding author

E-mail: shine2530@gmail.com
}

reports from the National Science and Technology Centre for Disaster Reduction, http://www.ncdr.nat.gov.tw/EarthquakeMeinong 1050206.aspx). This event is the deadliest earthquake in Taiwan since the 1999 Chi-Chi earthquake. This disaster was highly noted by seismologists and engineers, and raised the importance of seismic hazard assessment for this region.

Probabilistic seismic hazard analysis (PSHA; Cornell 1968), the most common methodology used nowadays for hazard assessment, determines the probability of exceedance $(\mathrm{PoE})$ for various levels of ground motion over a specified time period. It provides a key reference for mitigating seismic risk. The Taiwan Earthquake Model team (TEM), comprised of geologists, seismologists, and engineering seismologists, published the most recent seismic hazard model for Taiwan (TEM PSHA2015, Wang et al. 2016b). This model considered various seismic source topologies, i.e., shallowbackground area sources, seismogenic structure sources, and 
subduction zone sources. The seismogenic structure sources include both active and blind faults (Shyu et al. 2016). The GMPEs constructed by Lin and Lee (2008) and Lin (2009) were utilized to evaluate the ground shaking produced by different source typologies. The TEM PSHA2015 emphasized the high potential hazard in southern Taiwan, including Tainan City. It is necessary to examine the TEM hazard model retrospectively to understand its compatibility with the Meinong earthquake.

We analysed Meinong earthquake ground motions in the forms of peak ground acceleration (PGA), peak ground velocity (PGV), pseudo-spectral acceleration at $0.3 \mathrm{~s}$ (SA0.3) and $1.0 \mathrm{~s}$ (SA1.0), and shaking duration to examine their relation with the resulting damage. The PGA and PGV are the two most common ground motion intensity expressions. For engineering and seismological applications, ground shaking in the form of pseudo-spectral acceleration (SA) is often used to design structures. The SA0.3 and SA1.0 reflect the natural frequencies of low-rise buildings as approximately 3 storeys and high-rise building as approximately 10 storeys, respectively. The ground shaking duration is a critical factor because it reflects seismic hazards particularly in building performance, landslide triggering and liquefaction (Trifunac and Novikova 1995; Reinoso and Guerrero 2000; Hancock and Bommer 2005; Bommer et al. 2006; Kempton and Stewart 2006).

By disaggregating the TEM PSHA2015 hazard from different seismic sources, we analysed the contribution of various sources to seismic hazard in southern Taiwan. The Meinong earthquake occurred on a geologically unknown blind structure that was not identified in the TEM PSHA2015 seismogenic structures, and was attributed to the area source in TEM PSHA2015. Our results show that the 2016 Meinong earthquake did partially diminish the seismic hazard potential from area source. However, the seismic hazard potential in southern Taiwan remains high as the Meinong earthquake only released about $16 \%$ of the total seismic hazard potential for the seismic hazard potential for a return period of 475 years.

\section{STRONG MOTION DATA ANALYSIS}

\subsection{Damage Comparison to the Observed Peak Ground Motion and Response Spectra}

The Taiwan Strong Motion Instrumentation Program (TSMIP), network operated by the CWB, is composed of approximately 700 accelerographs at free field sites (Shin 1993) and has recorded high-quality strong ground motion data since 1993. In 2000, the National Centre for Research on Earthquake Engineering (NCREE) and the CWB committed to a free-field strong motion station drilling project to construct an Engineering Geological Database for the TSMIP (EGDT) (Fig. 1). A total 439 logging measurements were completed on sites belonging to the TSMIP network to obtain Vs30 (the average S-wave velocity of the top $30 \mathrm{~m}$ ) (Kuo et al. 2012). According to the Vs30-based provisions of the National Earthquake Hazard Reduction Program (NEHRP), the TSMIP free-field strong motion stations were divided into five site classes: A (hard rock with Vs30 higher than $1500 \mathrm{~m} \mathrm{~s}^{-1}$ ), B (firm to hard rock with Vs30 in between 1500 and $760 \mathrm{~m} \mathrm{~s}^{-1}$ ), $\mathrm{C}$ (dense soil and soft rock with Vs30 in between 760 and $360 \mathrm{~m} \mathrm{~s}^{-1}$ ), D (stiff soil with Vs30 in between 360 and $180 \mathrm{~m} \mathrm{~s}^{-1}$ ), and E (soft soil with Vs30 lower than $180 \mathrm{~m} \mathrm{~s}^{-1}$ ) classes. Most of the stations in the south-western Taiwan plain are on site classes D or E (Fig. 1).

We utilized the strong motion data received by the TSMIP network to analyse the PGA, PGV, SA0.3, and SA1.0 values of the Meinong earthquake. We followed the data processing procedures of Wang et al. (2016a) to remove the instrument response and correct the baseline for each ground motion recording. The high-pass filtering band on each acceleration time-series waveform was determined

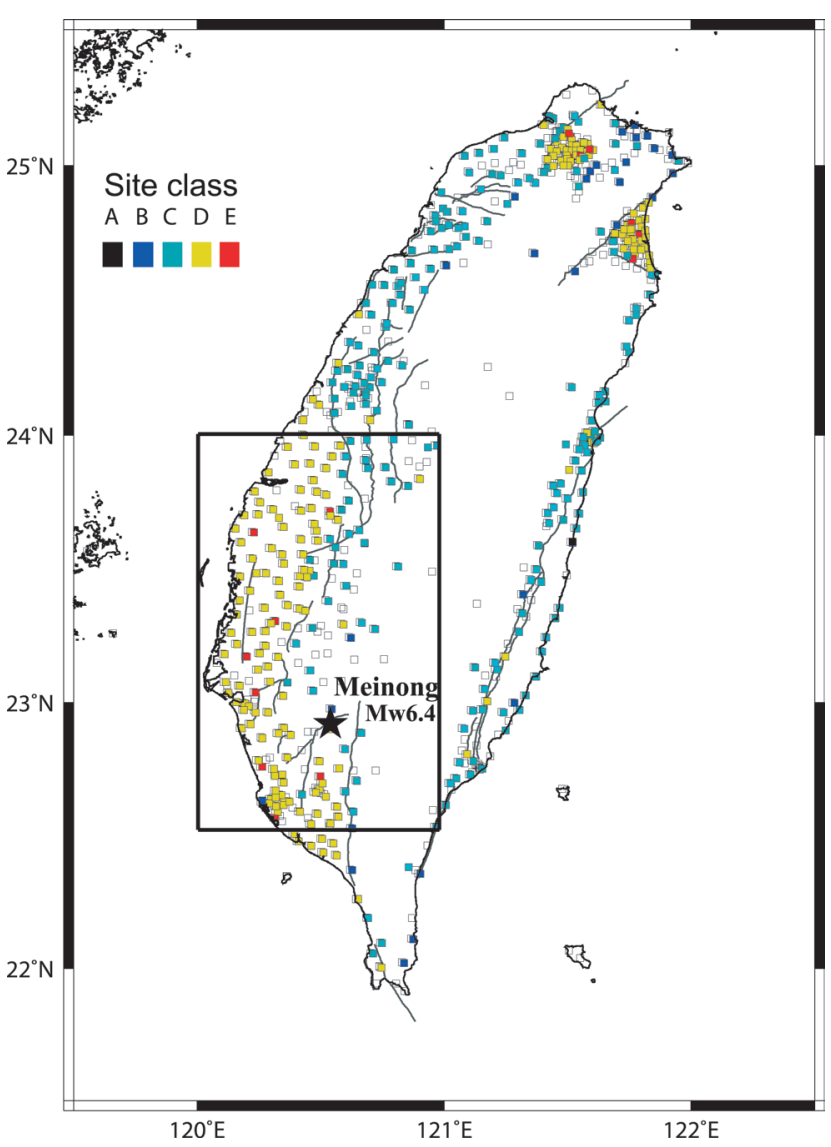

Fig. 1. Geographic distribution of TSMIP strong motion stations. The colours denote site classifications as determined by Kuo et al. (2012). The five site classes are A (hard rock with Vs30 higher than $1500 \mathrm{~m} \mathrm{~s}^{-1}$ ), B (firm to hard rock with Vs30 in between 1500 and $760 \mathrm{~m} \mathrm{~s}^{-1}$ ), C (dense soil and soft rock with Vs30 in between 760 and $360 \mathrm{~m} \mathrm{~s}^{-1}$ ), D (stiff soil with Vs30 in between 360 and $180 \mathrm{~m} \mathrm{~s}^{-1}$ ), and E (soft soil with Vs30 lower than $180 \mathrm{~m} \mathrm{~s}^{-1}$ ) classes. The star shows the epicentre of the 2016 Meinong earthquake. 
by examining the spectral amplitude ratio of signal to noise (RSN). For the acceleration response spectra (SA), we followed the Next Generation Attenuation (NGA) model to calculate the response spectrum with $5 \%$ critical-damping at the periods of 0.3 and $1.0 \mathrm{~s}$.

To provide an overall description of the damage in an area, we collected the data from buildings damaged in the Meinong event. There were 328 moderately damaged buildings (yellow squares in Fig. 2a) and 250 heavily damaged buildings (red squares in Fig. 2a), surveyed by the Tainan City government (http://data.tainan.gov.tw/dataset/0206earthquake). Another 11 extremely damaged buildings (Table 1) were listed by the official Meinong earthquake report by the National Centre for Research on Earthquake Engineering (2016). Figure 2 shows the locations of these buildings and the ground motion distribution (i.e., PGA, PGV, SA0.3, SA1.0, and duration) for the Meinong earthquake. Proximal to the 16-floor collapsed building, the Weiguan Jinlong building, the highest PGA $0.42 \mathrm{~g}$ was observed at station CHY062 (Fig. 2b), to the northwest of the epicentre. The highest PGV of ca. $60 \mathrm{~cm} \mathrm{~s}^{-1}$ was observed close to the Weiguan Jinlong building (Fig. 2c). The shake maps in the forms of SA0.3 and SA1.0 are presented in Figs. 2d and e with the highest values of 1.75 and $1.29 \mathrm{~g}$, respectively. To quantify the correlation between ground motion parameters (PGA, PGV, SA0.3, and SA1.0) and
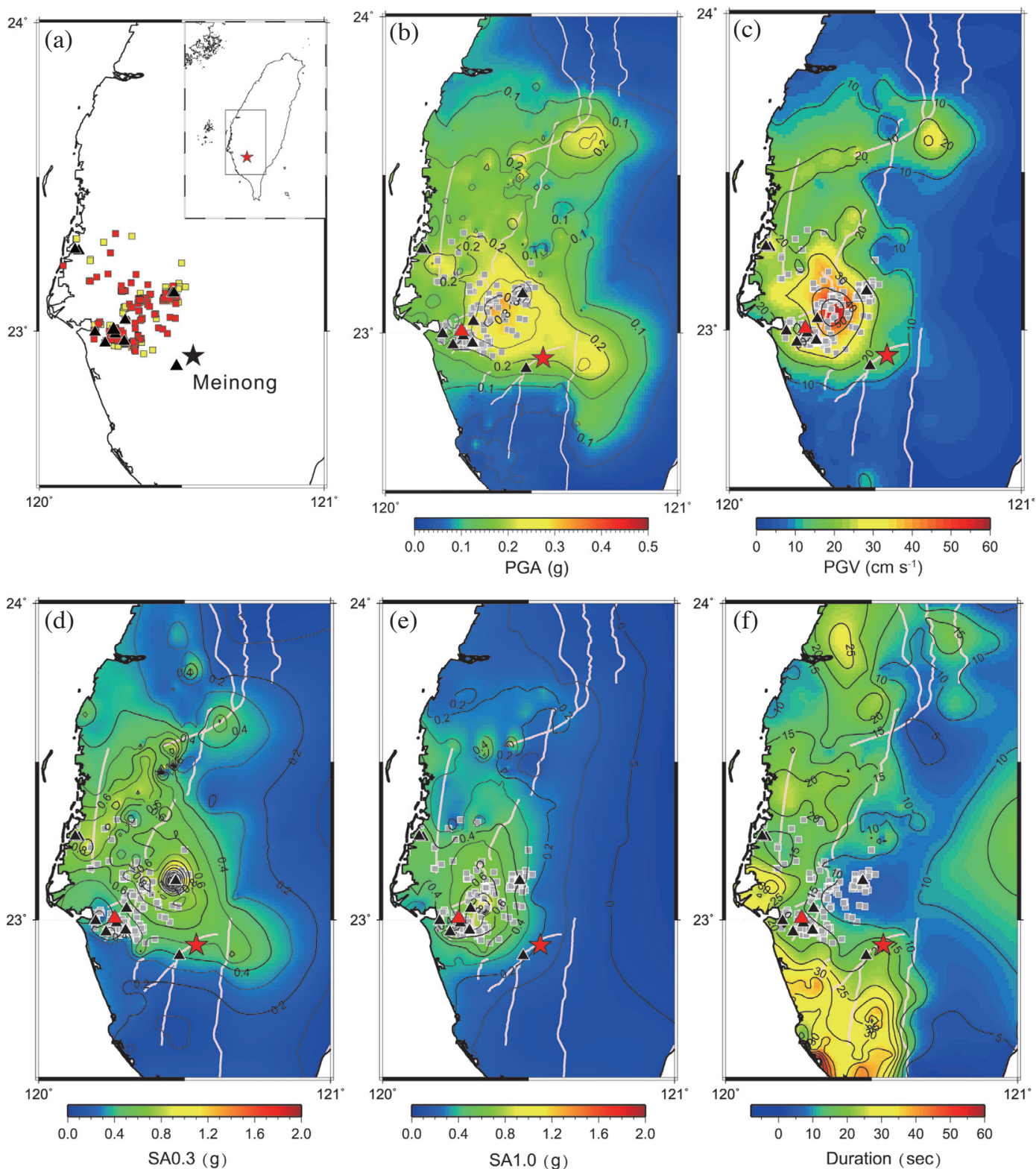

Fig. 2. Maps of (a) geographic distribution of damage buildings, (b) observed PGA, (c) PGV (d), SA0.3 (e), SA1.0, and (f) duration of the Meinong earthquake. Triangles show the locations of extremely damaged buildings caused by the earthquake provided by NCREE. Squares show the locations of moderately damaged buildings (in yellow) and heavily damaged buildings (in red) provided by the Tainan City government. 
Lee et al.

Table 1. Locations and corresponding ground shaking of the extreme damaged buildings caused by the Meinong earthquake announced by the NCREE official report.

\begin{tabular}{c|ccccccc}
\hline ID & LON $\left({ }^{\circ} \mathbf{E}\right)$ & LAT $\left({ }^{\circ} \mathbf{N}\right)$ & PGA $(\mathbf{g})$ & PGV $\left(\mathbf{c m ~ s}^{-1}\right)$ & SA0.3 (g) & SA1.0 (g) & Dur. $(\mathbf{s e c})$ \\
\hline A (Weiguan) & 120.253 & 23.007 & 0.15 & 18.96 & 0.37 & 0.38 & 17.21 \\
B & 120.293 & 23.038 & 0.11 & 21.98 & 0.76 & 1.29 & 15.59 \\
C & 120.223 & 22.964 & 0.22 & 31.69 & 0.63 & 0.74 & 17.55 \\
D & 120.188 & 23.000 & 0.19 & 25.73 & 0.45 & 0.35 & 18.45 \\
E & 120.290 & 22.969 & 0.22 & 31.69 & 0.63 & 0.74 & 17.55 \\
F & 120.474 & 22.888 & 0.20 & 15.09 & 0.61 & 0.53 & 21.88 \\
G & 120.259 & 22.992 & 0.15 & 18.96 & 0.37 & 0.38 & 17.21 \\
H & 120.460 & 23.126 & 0.42 & 25.32 & 1.75 & 0.43 & 6.39 \\
I & 120.462 & 23.126 & 0.42 & 25.32 & 1.75 & 0.43 & 6.39 \\
J & 120.131 & 23.263 & 0.16 & 27.56 & 0.74 & 0.52 & 14.58 \\
K & 120.117 & 23.267 & 0.16 & 27.56 & 0.74 & 0.52 & 14.58 \\
\hline
\end{tabular}

damaged buildings, we counted the damaged buildings within $3 \mathrm{~km}$ from the stations, of which the ground motion values are within the top $10 \%$ of observations. There are $63 \%$ damaged buildings around the stations with the highest 10-percentile PGA, 70\% damaged buildings for PGV, and 58 and $68 \%$ damaged buildings for SA0.3 and SA1.0, respectively. This result indicates that PGV and SA1.0 have a closer relationship to building damage.

\subsection{Comparison of Damage to the Shaking Duration}

We utilized the TSMIP data to analyse the shaking duration of sites during the Meinong earthquake. Lee et al. (2015) proposed a new definition of shaking duration called "Effective Shaking Duration (ESD)", which represents the amplitude and radiation energy decays. The ESD is defined as the period of dissipated energy within $5-95 \%$ of the total energy in a time window when the amplitude is greater than or equal to $0.01 \mathrm{~g}$. Figure $2 \mathrm{f}$ presents the ESD map for the Meinong earthquake. The longest duration of approximately up to $60 \mathrm{~s}$ was recorded at the station near the coast of southwestern Taiwan (KAU092) on a soft sediment site (Fig. 2f). Fortunately, due the moderate size of this earthquake, no correlation was found between the shaking duration and the damaged buildings. However, the longer shaking duration near the west coast might reflect the damage in the liquefaction region.

\subsection{Comparison Between Observed Ground Motion and Prediction of Empirical Attenuation Equations}

To compare the observed PGA, PGV, and SA0.3 and SA1.0 with the empirical attenuation equation estimation, we considered the GMPEs proposed by Lin et al. (2012) which was developed using the local records in Taiwan. The equation accounts for physical properties, including the source, geometric spreading, inelastic attenuation, and site effect in describing the ground motion:

$$
\begin{aligned}
\ln y= & C_{1}+F_{1}+C_{3}\left(8.5-M_{W}\right)^{2} \\
& +\left[C_{4}+C_{5}\left(M_{W}-6.3\right)\right] \ln \left\{\sqrt{\left[R^{2}+(\exp H)^{2}\right]}\right\} \\
& +C_{6} F_{N M}+C_{7} F_{R V}+C_{8} \ln (\mathrm{Vs} 30 / 1130) \\
F_{1}= & C_{2}\left(M_{w}-6.3\right) \text { where } M_{W} \leq 6.3 ; \\
F_{1}= & -H C_{5}\left(M_{w}-6.3\right) \text { where } M_{W}>6.3
\end{aligned}
$$

where $C_{1}$ to $C_{8}$ are the regression coefficients for the crustal earthquakes (Lin et al. 2012). Here we used moment magnitude $\left(M_{W}\right) 6.4$ and closest distance to the fault $(\mathrm{km})$ for $R$. We considered the Meinong fault model of Lee (2016) for $R$ estimation. $F_{N M}$ and $F_{R V}$ represent the earthquake type $\left(F_{N M}\right.$ $=1$ and $F_{R V}=0$ for normal fault earthquake; $F_{N M}=0$ and $F_{R V}$ $=1$ for reverse fault earthquake). Vs30 was determined using three site classes: Vs30 $=1130 \mathrm{~m} \mathrm{~s}^{-1}$ for hard-rock site, Vs30 $=360 \mathrm{~m} \mathrm{~s}^{-1}$ for soft-rock or stiff-soil site and Vs30 = $150 \mathrm{~m} \mathrm{~s}^{-1}$ for soft-soil site. Figures $3 \mathrm{a}$ - d present a comparison between the observed PGA, PGV, SA0.3, and SA1.0 and the estimation by the empirical attenuation equations. The results show that most of the observed PGA and PGV, in general, follow the same trend as the empirical equations prediction. However, significant outliers were observed for the region close to the fault, as within $10 \mathrm{~km}$, and a distance of about $80 \mathrm{~km}$ from the fault. The comparison also shows significant lower-prediction of the empirical equations for SA0.3, and SA1.0. Whether this feature is related to the source complexity of the Meinong earthquake, as indicated in Huang et al. (2016), or, due to a combination of radiation pattern, site and basin effect (Lee et al. 2016; Kanamori et al. 2017) further clarification is required.

We also considered the empirical equation of ESD constructed by Lee et al. (2015), which was constructed by 

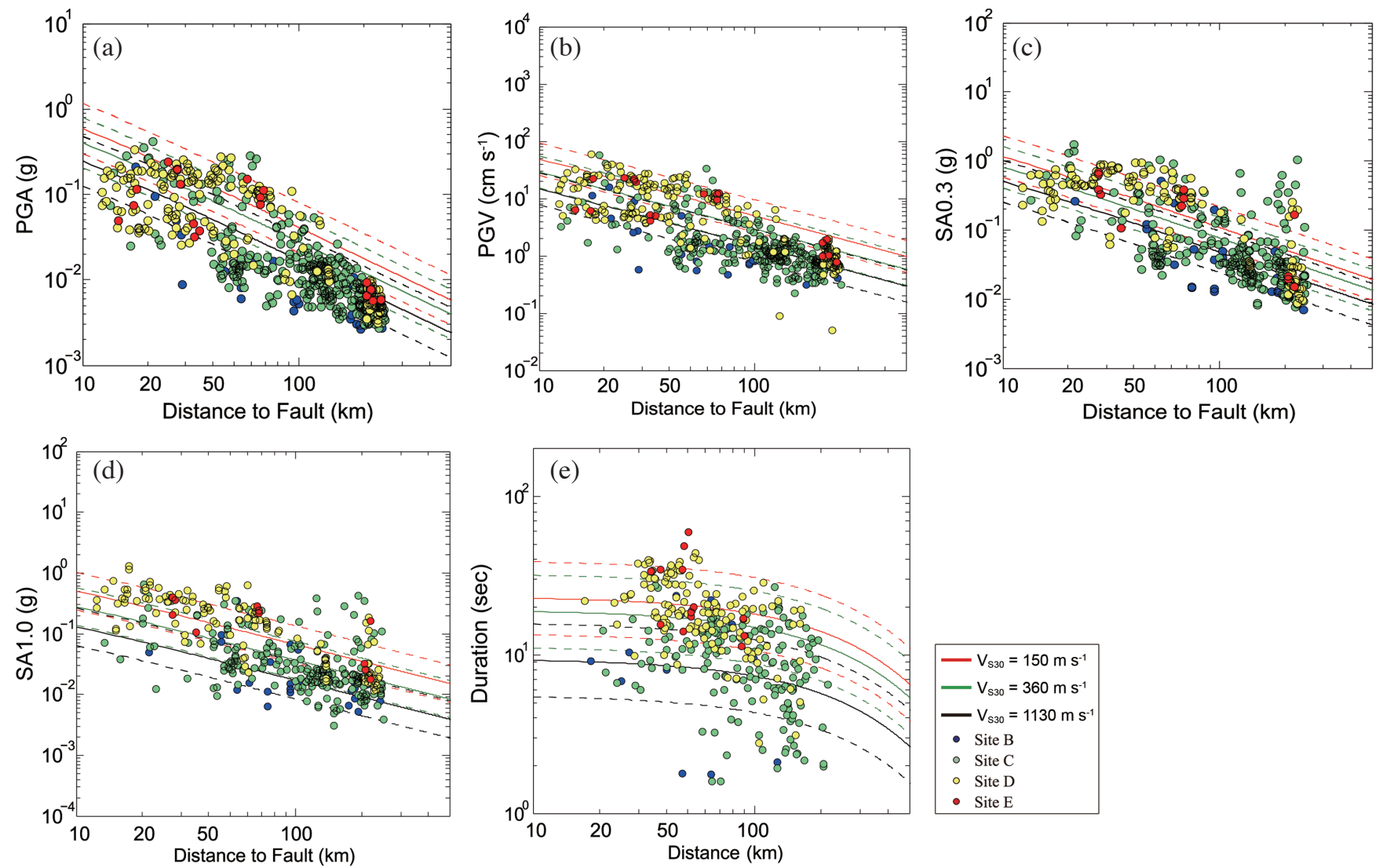

Fig. 3. Comparison between observations from the Meinong earthquake and the attenuation model developed by Lin et al. (2012) for (a) PGA, (b) PGV, SA for the following periods (c) $0.3 \mathrm{~s}$; (d) $1.0 \mathrm{~s}$; and (d) shaking duration by Lee et al. (2015). The solid lines are the median of the attenuation models and the dashed lines are curves for the median plus one standard deviation. The lines in red, green and black denote the attenuation model for the sites with Vs30 of 150,360 , and $1130 \mathrm{~m} \mathrm{~s}^{-1}$, respectively.

using the strong ground motion data of Taiwan earthquakes. This shaking duration equation is written as follows:

$\begin{aligned} \log \tau= & \log \left(\frac{\left\{\frac{\exp \left[b_{1}+b_{20}\left(M_{L}-5.57\right)\right]}{10^{1.5 M_{L}+16.05}}\right\}^{-1 / 3}}{4.9 \times 10^{6} \beta}\right) \\ & +c_{1} r_{h y p}+c_{2} V s 30+c_{3}\end{aligned}$

where $c_{1}, c_{2}$, and $c_{3}$ are regression coefficients of $c_{1}=-0.0011$, $c_{2}=-0.0004$, and $c_{3}=0.3038 ; b_{1}$ and $b_{2}$ are constants that determined as $b_{1}=1.1538$ and $b_{2}=1.3273 ; M_{L}$ is local magnitude; $r_{\text {hyp }}$ is hypocentre distance $(\mathrm{km})$. The standard deviation of Eq. (2) is 0.230. This empirical equation can be applied to earthquakes with magnitudes in the $5.0-7.3$ range. Figure $3 \mathrm{e}$ presents the comparison between the observed shaking duration and predicted ESD. The result shows that most of the observed data are comparable with estimations, except for two stations (KAU092 and KAU045) nearby the coast of southern Taiwan, which record slightly longer durations ( $>45 \mathrm{~s}$ ) probably because of local site-effect.

\section{THE CORRESPONDENCE BETWEEN DAMAGE AND GROUND-MOTION INTENSITY}

Seismic intensity is a quantity that describes the average level of damage generated by an earthquake. Seismic intensity estimation is crucial for hazard mitigation, especially for real-time earthquake rapid reports and early warning operations. The representative intensity index can well describe the damage, allowing comparison in the damaged buildings zone (denoted as 250 moderate damaged buildings, 328 heavy damaged buildings, and 11 extreme damaged buildings) with shaking maps from different groundmotion to intensity conversion equations (GMICE) (Fig. 4). We are aware that implementing different GMICEs may alter the patterns of intensity maps, the adaptability of GMICEs for the Meinong event; however, this is beyond the scope of this study. We consider three GMICEs which are the most commonly accepted in Taiwan.

An eight level instrumental intensity scale $(0-7)$ for Taiwan was delivered by the CWB based on PGA levels recorded over the past several decades. The instrumental 
intensity $\left(I_{t}\right)$ can be computed from PGA as:

$I_{t}=2.00 \cdot \log _{10}(\mathrm{PGA})+0.70$

where PGA is in gal (Hsu 1979; Wu et al. 2002). Alternatively, Wu et al. (2003) proposed a relationship between PGV and intensity as follows:

$I_{t}=2.14 \cdot \log _{10}(\mathrm{PGV})+1.89$

where PGV is in $\mathrm{cm} \mathrm{s}^{-1}$. Table 2 presents the definition of seismic intensity used in Taiwan, obtained from PGA and PGV. In addition, Fujimoto and Midorikawa (2005) proposed another intensity scale considering both PGA $\left(\mathrm{cm} \mathrm{s}^{-2}\right)$ and PGV $\left(\mathrm{cm} \mathrm{s}^{-1}\right)$ values, which is computed with the following equation:

$$
\begin{aligned}
& I_{t}=1.323+0986 \cdot \log _{10}(\mathrm{PGA} \cdot \mathrm{PGV})-0.079 \cdot \log _{10}(T) ; \\
& T=2 \pi \cdot(\mathrm{PGV} / \mathrm{PGA})
\end{aligned}
$$

where $T$ is the predominant period which describes the frequency characteristic of ground motion on response of site effect for the near-fault ground motions (Davoodi and Sadjadi 2015).

Figure 4 shows the seismic intensity maps obtained using the three GMICEs [Eqs. (3) - (5)]. The seismic intensity map based on PGA (Fig. 4a) shows high intensity over a large region, however, the damaged area, defined as the area having damaged buildings has less overlap proportion to the
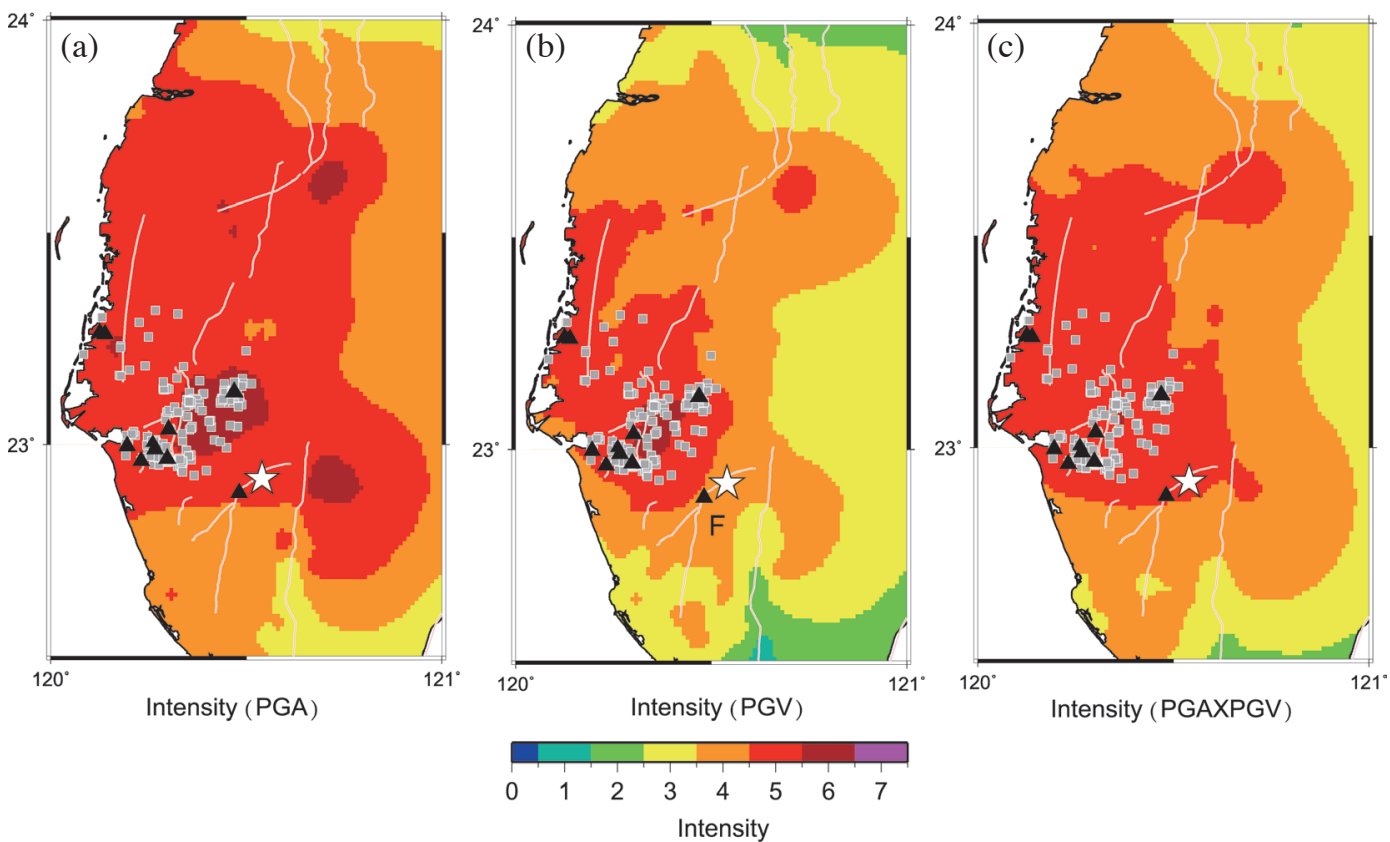

Fig. 4. The observed intensity maps based on (a) PGA, (b) PGV, and (c) PGA and PGV, respectively.

Table 2. A list of intensity scales based on PGA (CWB) and PGV (Wu et al. 2003) in Taiwan.

\begin{tabular}{cccc}
\hline Intensity $(\mathbf{C W B})$ & PGA $(\mathbf{G a l})$ & $\mathbf{P G V}\left(\mathbf{c m ~ s}^{-1}\right)$ & Perceived shaking \\
\hline 0 & $<0.8$ & 0.22 & Not felt \\
1 & $0.8-2.5$ & $0.22-0.65$ & Very light \\
2 & $2.5-8$ & $0.65-1.9$ & Light \\
3 & $8-25$ & $1.9-5.7$ & Weak \\
4 & $25-80$ & $5.7-17$ & Moderate \\
5 & $80-250$ & $17-49$ & Strong \\
6 & $250-400$ & $49-75$ & Violent \\
7 & $>400$ & $>75$ & Extreme \\
\hline
\end{tabular}


high intensity region. In Fig. 4b, the PGV-based intensity map shows better correspondence of the high intensity region to damaged building area, except for one moderately damaged building and one extremely damaged building F located in the region with intensity 4 . In Fig. 4c, the extent of high seismic intensity based on PGA $\times$ PGV is in between PGA-based and PGV-based intensity maps. The high intensity region has broader distribution, but includes all damaged buildings. The comparison indicates that the PGV-based intensity is the most representative index corresponding to the damage for the Meinong earthquake.
We calculated the hazard maps considering various seismic source topologies (Figs. 5 and 6) and the Meinong earthquake contribution to the PSHA (Fig. 7) to better analyse how the Meinong earthquake seismic source contributes to hazard. Three seismic source topologies were considered for PSHA: (1) shallow-background area sources: the earthquakes cannot be associated with a specific fault; (2) specific fault sources: the earthquakes are caused on particular active faults or seismogenic structures; and (3) subductionzone sources: the earthquakes occur in subduction zones.

For the shallow-background area sources, we applied the frequency-magnitude distributions of the seismicity to infer the recurrence intervals of the earthquakes in the source zone. The frequency-magnitude distributions can be

\section{PSHA IN SOUTHERN TAIWAN}

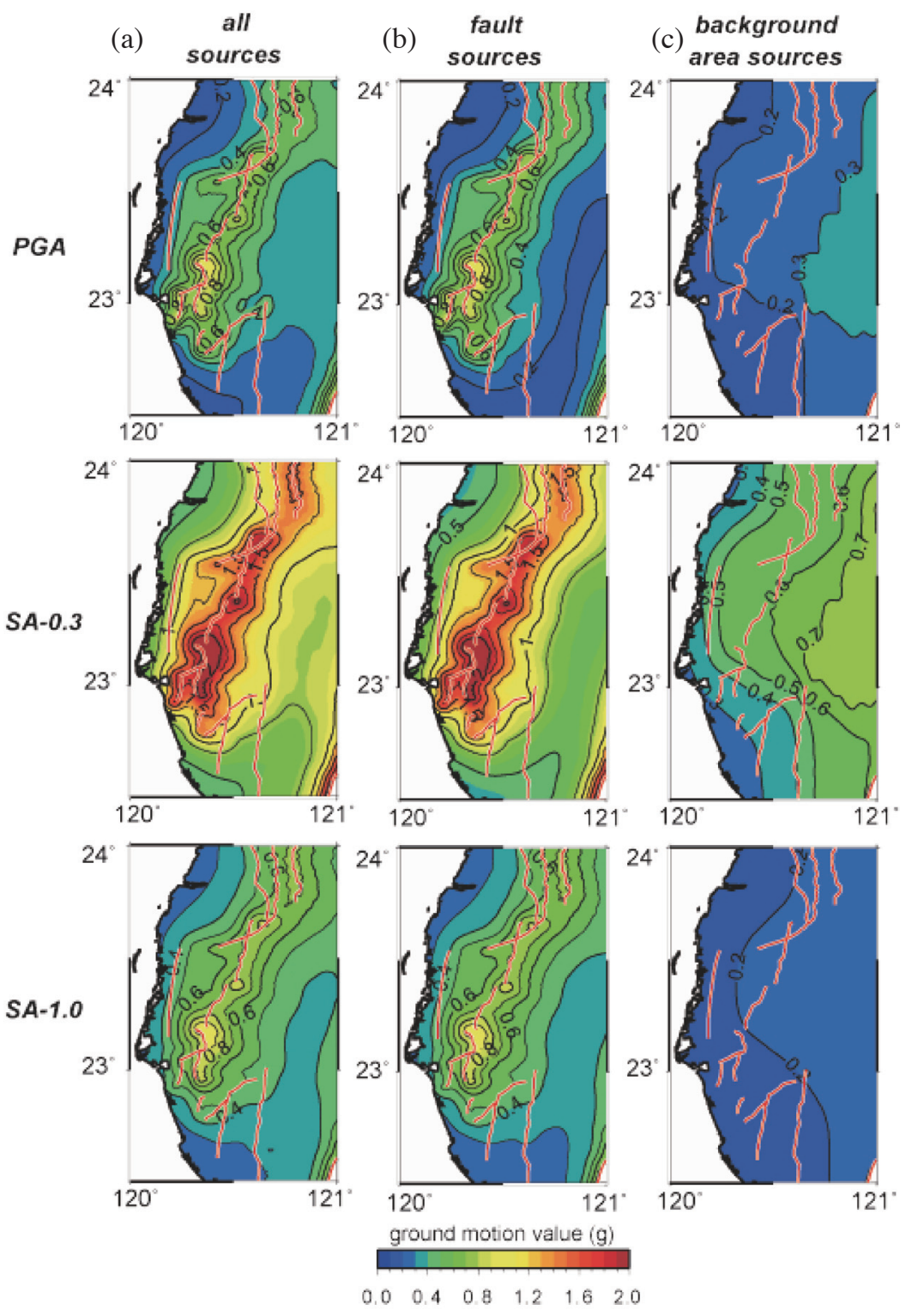

Fig. 5. Maps of PSHA maps obtained considering (a) all sources, (b) fault sources, and (c) background area sources with $10 \%$ PoE in 50 years (corresponding to a recurrence interval of 475 years) in PGA, SA at $0.3 \mathrm{~s}$ (SA-0.3), and SA at $1.0 \mathrm{~s}$ (SA-1.0) are shown. The PSHA results for hard rock sites $\left(\mathrm{Vs} 30=760 \mathrm{~m} \mathrm{~s}^{-1}\right)$. 


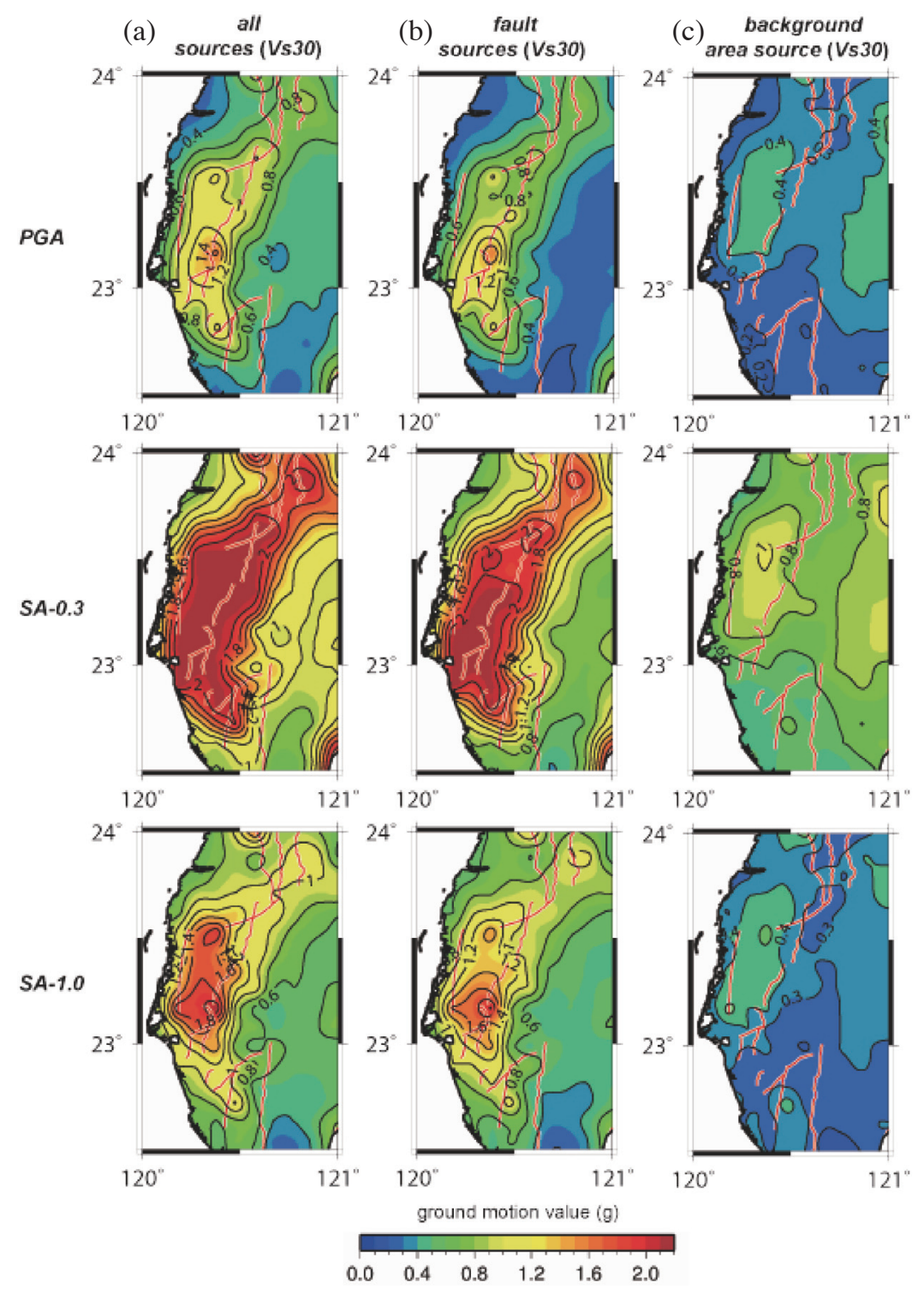

Fig. 6. Maps of PSHA maps obtained considering (a) all sources, (b) fault sources, and (c) background area sources and considering with local site effect (Vs30) with 10\% PoE in 50 years (corresponding to a recurrence interval of 475 years) in PGA, SA at $0.3 \mathrm{~s}$ (SA-0.3), and SA at 1.0 s (SA$1.0)$ are shown.

(a) PGA

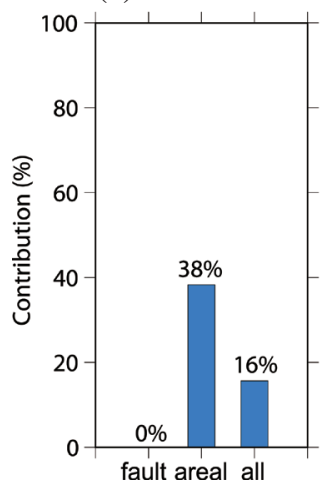

(b) SA 0.3

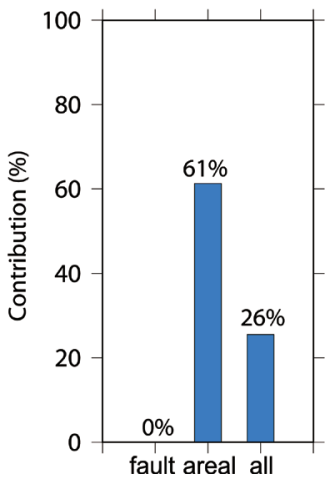

(c) SA 1.0

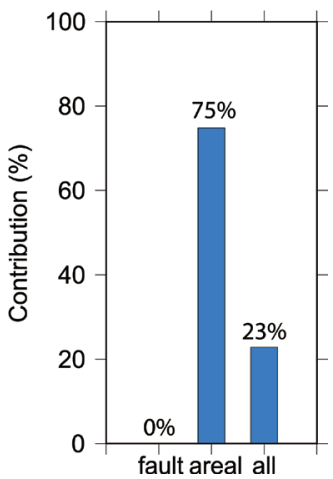

Fig. 7. The contributing ratio of the 2016 Meinong earthquake to the PSHA estimation (Fig. 6) considering active fault, shallow-background area and all of the sources in (a) PGA, (b) SA at $0.3 \mathrm{~s}$ (SA-0.3), and (c) SA at $1.0 \mathrm{~s}$ (SA-1.0). (Color online only) 
obtained by modelling seismicity activity according to the earthquake parameters from a catalogue. Although the first seismic station in Taiwan was initiated in the late $19^{\text {th }}$ century, before 1973 there were only 15 stations equipped with the Gray-Milne, Wiechert, and Omori seismographs. In this period, corresponding magnitude of completeness $\left(M_{c}\right)$ was about 4.3 - 4.8 (Chen et al. 2013). Afterward, the Taiwan Telemetric Seismic Network (TTSN) was operated, and $M_{c}$ decreased dramatically to about 2.0 - 3.0. In the early 1990 s, the TTSN stations were integrated into the Central Weather Bureau Seismic Network (CWBSN), the $M_{c}$ further decreased to about $1.5-2.5$. To consider the completeness of the CWBSN catalogue since 1993, the seismicity rate for each source is modelled based on the TTSN and CWBSN catalogues during 1973 and 2011. The utilized catalogue was processed with declustering using the Gardner and Knopoff algorithm (1974) to exclude the aftershocks. The seismogenic structures defined by Shyu et al. (2016) were adopted as the specific PSHA fault sources. The GMPEs of Lin and Lee (2008) and Lin (2009) were applied to crustal and subduction sources, respectively, to evaluate ground shaking.

The PSHA map for southern Taiwan was computed considering all sources mentioned above with a return period of 475 years (i.e., $10 \%$ PoE in 50 years) for PGA, SA 0.3, and SA 1.0 (Fig. 5a). To understand the hazard contributed by each source typology, the disaggregated PSHA maps for fault sources and shallow-background area sources are shown in Figs. 5b and c, respectively. The contributions to hazard from area and fault sources are 35 and $65 \%$, respectively, which is estimated using the proportion of hazard from each source in comparison with the total hazard. Since the Meinong earthquake occurred on an unidentified seismogenic structure, the earthquake hazard could be attributed to an unknown structure included in the area source. For comparison between the observed ground motion and TEM PSHA2015, we consider the site effect on the seismic hazard by employing the corresponding Vs30 of each station (Fig. 1) into the ground motion prediction. The results are shown in Fig. 6. The ground motions are significantly increased in western Taiwan due to the western plain and basin sedimentation. Figure 7 shows the disaggregation results statistics as the contributing ratio of the 2016 Meinong earthquake to the TEM PSHA2015 estimation with site effect. We utilized the Meinong earthquake observations to calculate the hazard percentages in different ground motion forms using the observation to the hazard from the PSHA map. The hazard values contributed by the Meinong earthquake are 16, 26, and $23 \%$ for PGA, SA0.3, and SA1.0, respectively; to the predicted seismic hazard of area source are 38,61 , and $75 \%$ for PGA, SA0.3, and SA1.0, respectively, for $10 \%$ PoE of 50 years PSHA. The result indicates that the 2016 Meinong earthquake did diminish partially the seismic hazard potential in southern Taiwan; however, more than about $80 \%$ of the seismic hazard potential was not yet released. These values suggest that the seismic hazard potential in southern Taiwan remains high regardless of the 2016 Meinong earthquake occurrence.

\section{DISCUSSION AND CONCLUSIONS}

We investigated the PGA, PGV, SA, and shaking duration characteristics generated by the Meinong earthquake and their possible links to hazard. According to our results, PGV and SA1.0 show better correlation with disaster (damaged buildings). Brendon (2012) analysed the correlation between PGV and SA referring to different periods and concluded that PGV has better correlation with SA1.0 than PGA and SA0.3. Additionally, Bommer et al. (2006) analysed the PGV/SA1.0 ratio with distance for moderate (M5) and large earthquakes (M7). Their results show that the PGV/ SA1.0 ratio is higher for shorter distance than longer distance; and is higher for a moderate earthquake than a larger earthquake. A large earthquake generates much long-period energy (SA1.0), which propagates with lower attenuation with distance. In addition, we presented the intensity maps converted from PGA and PGV values. The PGV-based intensity map can explain the damage distribution more relevantly. Most of the area with long duration is along the coast of southern Taiwan due to the soil site effect. In comparison, Wu et al. (2004) investigated the relationships between strong-motion peak values and losses during the 1999 ChiChi event. They found better correlation between the building damage distribution and PGV as well as SA1.0, rather than PGA. Similar earlier observations were found in Wald et al. (1999) for California earthquakes. This indicates that the damages are generally caused by relatively long-period waves rather a sharp high frequency impulse as often presented in PGA. A justification for the current intensity scale in Taiwan, which is mainly defined with only instrumental PGAs, to give more relation to PGVs might be necessary for further seismic risk assessments.

The Taiwan Earthquake Model (TEM) published a seismic hazard map of Taiwan at the end of 2015 (Wang et al. 2016b), and indicated a relatively high seismic hazard level in southern Taiwan. The hazard in Tainan may reach SA0.3 of $1.5 \mathrm{~g}$ with $10 \%$ PoE in 50 years, due to moderate earthquakes with short recurrence intervals and short distances. On the other hand, the observed ground shaking from the Meinong earthquake is $1.75 \mathrm{~g}$ in SA0.3. A lower hazard predicted by TEM PSHA2015 can be attributed to a median TEM PSHA2015 prediction value, which considered only the relative rock site as Vs30 $=760 \mathrm{~m} \mathrm{~s}^{-1}$. In addition, Wang et al. (2016c) disaggregated the hazard from the magnitude intervals for southern Taiwan. Their results indicate that the seismic hazard in southern Taiwan was dominated by M 6.0-class earthquakes. The faults with short lengths (corresponding to small slip of each rupture) and high slip rates result in high seismic hazard probabilities. The earthquake 
probabilities with $\mathrm{M}_{\mathrm{w}}>6.5$ occurring in southern Taiwan is up to $82 \%$ in 50 years and the seismogenic structure with the highest rupture probability in the Tainan region is the Houchiali fault (44\% in 50 years). Our disaggregated PSHA statistics (Fig. 7) show that the seismic source contribution to hazard is mainly from fault sources. The Meinong earthquake occurred in an unknown blind structure attributed to the TEM PSHA2015 area source. However, the hazard contributed by fault sources is much higher than that by the background area sources in southern Taiwan (Fig. 7). The high hazard potential from fault sources in southern Taiwan due to the densely distributed seismogenic structures with short recurrence intervals still require special attention regardless of the 2016 Meinong earthquake occurrence.

Acknowledgements The authors are grateful for research support from the Ministry of Science and Technology (MOST) and the Department of Earth Sciences, National Central University, Taiwan, ROC. Thanks to the Central Weather Bureau Seismological Network for providing high-quality seismic data. This research was supported by funding through MOST, with project grant number MOST 103-2116-M008-008-MY3 and the Taiwan Earthquake Research Centre (TEC) funded through MOST, formerly the National Science Council (NSC), with Taiwan Earthquake Model (TEM) project grant number MOST 105-2119-M-006-016.

\section{REFERENCES}

Bommer, J. J., J. Hancock, and J. E. Alarcón, 2006: Correlations between duration and number of effective cycles of earthquake ground motion. Soil Dyn. Earthq. Eng., 26, 1-13, doi: 10.1016/j.soildyn.2005.10.004. [Link]

Brendon, A. B., 2012: Empirical Correlations between peak ground velocity and spectrum-based intensity measures. Earthq. Spectra, 281, 17-35, doi:10.1193/1.3675582 [Link]

Chen, C. H., J. P. Wang, Y. M. Wu, C. H. Chan, and C. H. Chang, 2013: A study of earthquake inter-occurrence times distribution models in Taiwan. Nat. Hazards, $\mathbf{6 9}$, 1335-1350, doi: 10.1007/s1 1069-012-0496-7. [Link]

Cornell, C. A., 1968: Engineering seismic risk analysis. Bull. Seismol. Soc. Am., 58, 1583-1606.

Davoodi, M. and M. Sadjadi, 2015: Assessment of nearfield and far-field strong ground motion effects on soil-structure SDOF system. IJCE, 13, 153-166, doi: 10.22068/IJCE.13.3.153. [Link]

Fujimoto, K. and S. Midorikawa, 2005: Empirical method for estimating J.M.A. instrumental seismic intensity from ground motion parameters using strong motion records during recent major earthquakes. J. Social Safety Sci., 7, 1-6. (in Japanese)

Gardner, J. K. and L. Knopoff, 1974: Is the sequence of earthquakes in Southern California, with aftershocks removed, Poissonian? Bull. Seismol. Soc. Am., 64, 1363-1367.

Hancock, J. and J. J. Bommer, 2005: The effective number of cycles of earthquake ground motion. Earthq. Eng. Struct. Dyn., 34, 637-664, doi: 10.1002/eqe.437. [Link]

Hsu, M. T., 1979: Seismology, Li Ming Cultural Enterprise Co., Ltd., Taipei, Taiwan, 16-26. (in Chinese)

Huang, M. H., H. Tung, E. Fielding, H. H. Huang, C. Liang, C. Huang, and J. C. Hu, 2016: Multiple fault slip triggered above the $2016 \mathrm{Mw} 6.4$ MeiNong earthquake in Taiwan. Geophys. Res. Lett., 43, 7459-7467, doi: 10.1002/2016GL069351. [Link]

Kanamori, H., L. Ye, B.-S. Huang, H.-H. Huang, S.-J. Lee, W.-T. Liang, Y.-Y. Lin, K.-F. Ma, Y.-M. Wu, and T.-Y. Yeh, 2017: A strong-motion hot spot of the 2016 Meinong, Taiwan, earthquake $\left(\mathrm{M}_{\mathrm{w}}=6.4\right)$. Terr. Atmos. Ocean. Sci., 28, 637-650, doi: 10.3319/ TAO.2016.10.07.01. [Link]

Kempton, J. J. and J. P. Stewart, 2006: Prediction equations for significant duration of earthquakes ground motions considering site and near source effects. Earthq. Spectra, 22, 985-1013, doi: 10.1193/1.2358175. [Link]

Kuo, C.H., K. L. Wen, H. H. Hsieh, C. M. Lin, T. M. Chang, and K. W. Kuo, 2012: Site classification and Vs30 estimation of free-field TSMIP stations using the logging data of EGDT. Eng. Geol., 129, 68-75, doi: 10.1016/j. enggeo.2012.01.013. [Link]

Lee, S. J., 2016: Analysis of the source rupture model of Meinong earthquake with Mw6.4 on February 6, 2016. TEM 105/02/06 Meinong earthquake $\left(\mathrm{M}_{\mathrm{L}} 6.4\right)$ conference. Available at http://tec.earth.sinica.edu.tw/new web/upload/news/Conference/20160206meilongEQ/0 217_section02_03.pdf.

Lee, S. J., T. Y. Yeh, and Y. Y. Lin, 2016: Anomalously large ground motion in the $2016 \mathrm{M}_{\mathrm{L}} 6.6$ Meinong, Taiwan, earthquakes: A synergy effect of source rupture and site amplification. Seismol. Res. Lett., 87, 13191326, doi: 10.1785/0220160082. [Link]

Lee, Y. T., K. F. Ma, Y. J. Wang, and K. L. Wen, 2015: An empirical equation of effective shaking duration for moderate to large earthquakes. Nat. Hazards, $\mathbf{7 5}$, 1779-1793, doi: 10.1007/s11069-014-1398-7. [Link]

Lin, P. S., 2009: Ground-motion attenuation relationship and path-effect study using Taiwan Data set. Ph.D. Thesis, Institute of Geophysics, National Central University, Chung-Li, Taiwan, 157 pp. (in Chinese)

Lin, P. S. and C. T. Lee, 2008: Ground-motion attenuation relationships for subduction-zone earthquakes in northeastern Taiwan. Bull. Seismol. Soc. Am., 98, 220-240, doi: 10.1785/0120060002. [Link]

Lin, P. S., P. S. Hsie, Y. R. Lee, C. T. Cheng, and K. S. Shao, 2012: The research of probabilistic seismic hazard analysis and geological survey of nuclear power 
plant: Construction of ground motion prediction equation for response spectra. Commission Report of the Institute of Nuclear Energy Research, Atomic Energy Council, Executive Yuan. (in Chinese)

National Centre for Research on Earthquake Engineering, 2016: Meinong Earthquake Information. Retrieve March 2, 2016. Available at http://www.ncree.org/ EarthquakeInfo/2016-0206/20160206\%E9\%AB\%98 $\% \mathrm{E} 9 \% 9 \mathrm{~B} \% 84 \% \mathrm{E} 7 \% \mathrm{BE} \% 8 \mathrm{E} \% \mathrm{E} 6 \% \mathrm{BF} \% 83 \% \mathrm{E} 5 \% 9 \mathrm{C}$ \% $0 \% \mathrm{E} 9 \% 9 \mathrm{C} \% 87 \% \mathrm{E} 5 \% \mathrm{BD} \% 99 \% \mathrm{E} 6 \% 95 \% \mathrm{~B} 4 \% \mathrm{E} 7$ $\% \mathrm{~B} 0 \% \mathrm{~A} 1 \% \mathrm{E} 5 \% \mathrm{~A} 0 \% \mathrm{~B} 1 \mathrm{~V} 5.0$ ENG.pdf.

Reinoso, E. M. O. and R. Guerrero, 2000: Influence of strong ground-motion duration in seismic design of structures. Proceedings of the 12th World Conference on Earthquake Engineering, paper 1151, Aukland, New Zealand National Society for Earthquake Engineering.

Shin, T. C., 1993: Progress summary of the Taiwan strongmotion instrumentation program. Symposium on the Taiwan Strong Motion Program, Central Weather Bureau, Taipei, 1-10.

Shyu, J. B. H., Y. R. Chuang, Y. L. Chen, Y. R. Lee, and C. T. Cheng, 2016: A new on-land seismogenic structure source database from the Taiwan Earthquake Model (TEM) project for seismic hazard analysis of Taiwan. Terr. Atmos. Ocean. Sci., 27, 311-323, doi: 10.3319/ TAO.2015.11.27.02(TEM). [Link]

Trifunac, M. D. and E. I. Novikova, 1995: Duration of earthquake fault motion in California. Earthq. Eng. Struct. Dyn., 24, 781-799, doi: 10.1002/eqe.4290240602. [Link]

Wald, D. J., V. Quitoriano, T. H. Heaton, and H. Kanamori, 1999: Relationships between peak ground accelera- tion, peak ground velocity and Modified Mercalli Intensity in California. Earthq. Spectra, 15, 557-564, doi: 10.1193/1.1586058. [Link]

Wang, Y. J., Y. T. Lee, K. F. Ma, and Y.C. Wu, 2016a: New attenuation relationship for peak ground and pseudospectral acceleration of normal-faulting earthquakes in offshore northeast Taiwan. Terr. Atmos. Ocean. Sci., 27, 43-58, doi: 10.3319/TAO.2015.08.17.01(T). [Link]

Wang, Y. J., C. H. Chan, Y. T. Lee, K. F. Ma, J. Bruce H. Shyu, R. J. Rau, and C. T. Cheng, 2016b, Probabilistic seismic hazard assessment for Taiwan. Terr. Atmos. Ocean. Sci., 27, 325-340, doi: 10.3319/ TAO.2016.05.03.01(TEM). [Link]

Wang, Y. J., Y. T. Lee, C. H. Chan, and K. F. Ma, 2016c: An investigation on the reliability of the Taiwan Earthquake Model PSHA2015. Seismol. Res. Lett., 87, 1287 1298, doi: 10.1785/0220160085. [Link]

Wu, Y. M., N. C. Hsiao, T. L. Teng, and T. C. Shin, 2002: Near real-time seismic damage assessment of the rapid reporting system. Terr. Atmos. Ocean. Sci., 13, 313324, doi: 10.3319/TAO.2002.13.3.313(CCE). [Link]

Wu, Y. M., T. L. Teng, T. C. Shin, and N. C. Hsiao, 2003: Relationship between peak ground acceleration, peak ground velocity, and intensity in Taiwan. Bull. Seismol. Soc. Am., 93, 386-396, doi: 10.1193/1.1586058. [Link]

Wu, Y. M., N. C. Hsiao, and T. L. Teng, 2004: Relationships between strong ground motion peak values and seismic loss during the 1999 Chi-Chi, Taiwan earthquake. Nat. Hazards, 32, 357-373, doi: 10.1023/B:NHAZ.0000035550.36929.d0. [Link] 